\title{
Opium poppy capsule growth and alkaloid production is constrained by shade during early floral development
}

\author{
Elliana Hope ${ }^{1} \mid$ Madeline Rose Carins-Murphy $^{2}$ | Corey Hudson ${ }^{3}$ | Les Baxter ${ }^{3}$ | Alistair
} Gracie $^{1}$

${ }^{1}$ Tasmanian Institute of Agriculture, College of Sciences and Engineering, University of Tasmania Private Bag 54, Hobart, Australia 7001,

${ }^{2}$ School of Natural Sciences, College of Sciences and Engineering, University of Tasmania Private Bag 55, Hobart, Australia 7001,

${ }^{3}$ Tasmanian Alkaloids, PO Box 130, Westbury, Tasmania, Australia, 7303.

\section{Correspondence}

Alistair Gracie, Tasmanian Institute of Agriculture, College of Sciences and Engineering, University of Tasmania Private Bag 54, Hobart, Australia 7001. Email: Alistair.Gracie@utas.edu.au may lead to differences between this version and the Version of Record. Please cite this article as doi: 10.1111/aab.12581 


\section{Abstract}

Morphinan alkaloids accumulate in the capsules of Papaver somniferum L. (opium poppy) most likely as defence against herbivory. Thus, capsule size is an important component of alkaloid yield. Shade during early cell division-dominated growth of reproductive structures generally reduces final fruit size more than shade during later cell expansion-dominated growth. The current study aimed to determine whether this response is found in opium poppy and the subsequent impact on alkaloid yield, composition, and seed production. First the timing of key reproductive developmental events was resolved relative to macro-morphological traits. Plants were then shaded during either (i) floral initiation, (ii) early floral development, or (iii) capsule expansion before being harvested at maturation. Shade during floral initiation dramatically reduced final capsule size, alkaloid yield, and seed number, and increased the concentration of precursor compounds relative to morphine, despite plants later returning to full sun. Shade during later capsule growth enhanced capsule size and alkaloid yield but had little effect on alkaloid composition or seed number. Thus, early developmental processes, including morphine biosynthesis, appear to have a relatively greater demand for carbohydrates compared with later processes. Crop management practices and environmental factors that limit carbohydrate availability during early development are thus predicted to have significant negative impacts on alkaloid production and reproductive success.

\section{Keywords}

Papaver somniferum L., opium poppy, capsule, seed, alkaloid, shade, floral initiation, floral development, carbohydrate limitation.

\section{1 | Introduction}


The predominant alkaloids extracted from the fruit (capsule) of opium poppy (Papaver somniferum L.) to meet global pharmaceutical market demand for analgesic products are morphine, oripavine, codeine, and thebaine (collectively referred to in this study as MOCT alkaloids). These alkaloids are produced via the morphinan pathway which splits at the precursor alkaloid thebaine to produce morphine via two routes; either through main intermediates thebaine and codeine, or through oripavine (Beaudoin \& Facchini 2014). The biosynthesis and storage of these compounds in opium poppy involves three cell types: the sieve elements, companion cells, and laticifers (Facchini \& De Luca, 1995; Bird et al., 2003; Samanani et al., 2006; Lee \& Facchini, 2010). Briefly, the enzymes involved with biosynthesis are transported from companion cells to the sieve elements where most biosynthesis occurs, while further biosynthesis and final storage takes place in the cytoplasm (or latex) of the laticifers (Beaudoin \& Facchini, 2014). Differentiation of laticifers from meristematic cells occurs simultaneously with the development of other phloem tissues (Evert, 2006; Hagel et al., 2008) alongside overall capsule growth (Bernáth, 1998). Thus, there are positive linear relationships between capsule dry weight and both latex and morphine yield per capsule, and between capsule size and seed yield per plant, meaning that larger capsules have a greater mass of latex and morphine and a higher chance of reproductive success (Harvest et al., 2009; Singh et al., 2003). Alkaloids are thought to play an important role in defense from herbivory and hence a positive association between seed number and alkaloid yield per capsule is advantageous for species fitness (Lee et al., 2013).

Understanding variation in resource requirements during reproductive development is crucial for growers to maximize crop yield. Shading (i.e. limiting carbohydrate availability) has a negative overall impact on plant growth in opium poppy (Bernáth \& Tétényi, 1979). Bernáth \& Tétényi, (1979) found that plants that received lower irradiance prior to the transition from 
vegetative to reproductive growth tended to produce capsules with lower dry weight and alkaloid concentration compared with those that received higher irradiance throughout both vegetative and reproductive growth. This suggests that the processes involved with floral initiation and early floral growth are sensitive to the light environment, and thus, may have relatively high carbohydrate requirements. It also suggests that subsequent growth at later stages of development cannot compensate for any adverse effects of low irradiance during early growth on final capsule characteristics. However, it is not known whether later stages of floral and capsule development also have a high carbohydrate requirement and to what extent low irradiance during these later stages impacts capsule size, alkaloid yield, and seed production.

Extensive research in other species has found that carbohydrate availability has a differential influence on final fruit morphology during key developmental stages (Matthews and Anderson, 1988; Turner, 1990). This has been widely observed both by manipulating source tissues through defoliation and sink tissues via fruit thinning at various stages of development (Hunter \& Visser, 1990; Link, 2000; Morandi et al., 2008; Zhou et al., 2000). It has been shown that the timing of carbohydrate availability during fruit development can affect the magnitude, and direction, of any impacts on final fruit morphology, presumably due to variation in carbohydrate use among different phases of growth. This may be a result of the relative capacity of different plant organs to compete for carbohydrates produced by photosynthesis, their relative "sink strength" (Ho, 1988), as well as whether growth is predominantly driven by cell division, cell expansion, or both. Fruit often develop at the expense of vegetative growth, whereas flowers generally have a relatively weaker ability to compete for carbohydrates (Wardlaw, 1968, 1990; Leonard, 1962). Given that early floral growth is dominated by cell division and is a weak competitor for carbohydrates (Coombe, 1976; Ho, 1988), reducing carbohydrate availability at this time is likely to reduce the total 
number of cells per floral organ and may impact final fruit morphology. In contrast, because later stages of fruit growth are dominated by cell expansion (which is more affected by water availability than carbohydrate supply (Kriedemann, 1986)), and because developing fruit can divert carbohydrates from other organs (Leonard, 1962), growth at this stage may be less impacted by reduced carbohydrate availability. In support of this, darkness during early phases of fruit growth in tomato reduces fruit final dry weight more than shading during later phases that are dominated by cell expansion (Baldet et al., 2002). Thus, reducing carbohydrate availability during early stages of capsule development, for example during floral initiation, when growth is likely dominated by cell division may have more detrimental impact on final poppy capsule characteristics than at later stages dominated by cell expansion. However, the timing and duration of these specific phases of floral initiation in the apical meristem, and cell division and expansion during capsule growth relative to whole plant development is yet to be resolved in opium poppy. In a similar way, resource limitation may also influence aspects of seed production independent from the effectiveness of pollination (Strenlin \& Aizen, 2018). Carbohydrate limitation during vegetative or early reproductive development may reduce the number of ovules produced ultimately limiting seed number. Whereas, during later fruit development and expansion, the embryo quality or seed weight of fertilised seed may be limited (Strenlin \& Aizen, 2018).

The composition of morphinan alkaloids present in mature opium poppy capsules also appears to be affected by the timing of shade during plant development (Bernáth \& Tétényi, 1979; Mahdavi-Damghani et al., 2010). The concentration of precursor compounds thebaine and codeine in the capsules of two cultivars 'Kék Duna' and 'Kompolti M' at harvest declined when plants were shaded before the transition to reproductive growth (Bernáth \& Tétényi, 1979). However, it is not known whether shade during other stages of floral and capsule development also alters capsule alkaloid composition. Whole plant growth slows with 
decreasing light intensity, thus precursor compounds may be present in smaller relative concentrations at harvest due to an extended period of conversion of fewer total precursors to morphine (Bernáth \& Tétényi, 1979). If biosynthesis is linked to overall growth rate, shading during early floral development (a period of rapid growth) may have greater influence on alkaloid composition than shade at later developmental stages when growth is likely to be slowing. Specifically, it is possible that shading during floral initiation and early floral development slows plant development and lowers final concentrations of precursor compounds relative to morphine.

A bottleneck to progress in this area is that currently the timing of key events during opium poppy capsule development (e.g. floral initiation and the onset of capsule expansion) in relation to whole plant morphological changes remain undefined. Thus, in this study, we first link the timing of key reproductive developmental events with time after sowing and plant morphological changes. We then use this information to test our first hypothesis that early reproductive development has a relatively greater carbohydrate requirement than later development, and that limiting carbohydrate availability by shading plants during floral initiation and early floral development will have a more detrimental effect on final capsule size, seed number and alkaloid yield than shade during later stages of growth (i.e. capsule expansion). We then test our second hypothesis that shade during early reproductive development will alter the relative concentrations of precursor and end-product alkaloids more than shade at later stages. Specifically, we test whether shade during earlier floral development increases the concentration of morphine at harvest relative to earlier precursor compounds thebaine, oripavine and codeine.

\section{2 | Materials and Methods}




\section{1 | Plant material and growth conditions}

Opium poppy (Papaver somniferum 'Morphine PW11-3544') seeds were obtained from Tasmanian Alkaloids Pty Ltd. Plants were grown from seed in a glasshouse under a $16 \mathrm{~h}$ photoperiod (natural light was supplemented and extended in the morning and evening by 400W mercury vapour lamps). Mean temperature was $22^{\circ} \mathrm{C}$, maximum PPFD was $1900 \mu \mathrm{mol}$ $\mathrm{m}^{-2} \mathrm{~s}^{-1}$ at the soil surface and mean relative humidity was $63.4 \%$. All plants were grown in eight-inch diameter pots containing pine bark (90\%), coarse potting sand (5\%) and coco peat (5\%) and experienced the same conditions until three weeks after sowing. At this time four plants were used to determine the timing of floral initiation relative to changes in whole plant morphology. A further 60 plants were allocated to one of five treatments (12 plants per treatment) in a completely randomised design. These treatments comprised shading at different growth stages using shade cloth that blocked approximately $60 \%$ of sunlight. Timing of shading was based on the estimated timing of change in vegetative and reproductive development established in this study. Consequently, plants were shaded either (i) from 3-6 weeks after sowing to coincide with floral initiation, (ii) from six to nine weeks after sowing during early floral development, or (iii) from nine to eleven weeks after sowing during capsule expansion. Additional plants were either shaded or experienced full sun continuously from $3-11$ weeks after sowing. All plants received regular abundant irrigation from sowing to anthesis. At the same time in a separate experiment investigating the effect of water limitation on capsule development and alkaloid accumulation, water supply to 36 plants was restricted during the same three developmental stages. This data will only be included here to examine the relationships between capsule morphology and alkaloid characteristics. Additionally, three of the plants shaded continuously were damaged prior to anthesis and were therefore excluded from the dataset. 
2.2 Timing of events during reproductive development

Environmental scanning electron microscopy (ESEM) was used to examine the apical meristem of poppy plants harvested three to four weeks after sowing to identify the transition from vegetative to reproductive development (floral initiation) and other significant events during reproductive development. The timing of each developmental event was observed and the number of fully emerged leaves ( $>1 \mathrm{~cm}$ length) and nodes were recorded in representative plants. Changes to the apical meristem during the transition to reproductive growth in opium poppy were compared with similar changes to the apical meristem in the closely related California poppy (Eschscholzia californica Cham.) (Becker et al., 2005) to identify vegetative and floral structures.

\section{3 | Plant and capsule morphology}

Following plant senescence, whole plant, vegetative stem, and pedicel height, as well as, vegetative stem and pedicel diameter was recorded for each of the plants that underwent the five shade treatments. Vegetative height was defined as the stem length from the cotyledon scar to the youngest leaf node, and pedicel height as the length from the youngest leaf node to the widest point below the capsule (gynophore). Whole plant height was then calculated as the sum of vegetative stem and pedicel height. Vegetative stem diameter was measured at the approximate mid-point of the vegetative stem, and pedicel diameter $2 \mathrm{~cm}$ below the gynophore using digital calipers $(150 \mathrm{~mm}$ stainless steel digital vernier caliper, Craftright, China).

Primary capsules were then removed at the gynophore from each plant (including those that were part of the restricted water supply experiment) and stored out of direct sunlight until alkaloid quantification. Capsule height and width were also measured using digital calipers. Capsule height was measured from the rounded base of the capsule to the top of the stigmatic 
rays. Orthogonal measurements of capsule width were made with reference to the widest point of the capsule (width A and width B). Capsule volume was then estimated using the following equation for the volume of an ellipsoid:

capsule volume $\left(\mathrm{cm}^{3}\right)=\left(\frac{4}{3}\right) \times \pi \times \frac{\left(\left(\frac{\text { height }}{10}\right) \times\left(\frac{\text { width } A}{10}\right) \times\left(\frac{\text { width } B}{10}\right)\right)}{2}$

\section{$2.4 \mid$ Seed number and alkaloid quantification}

Following capsule morphological measurements, seed number, and alkaloid yield and composition was quantified for each capsule. Seeds were removed and counted using a Contador automatic seed counter (Pfeuffer, Germany). The air-dried capsule tissue was ground using a kitchen spice grinder (Home Collection, China) for $25 \mathrm{~s}$. This ground tissue was then weighed, and alkaloids extracted using a $2.0 \mathrm{~g}$ to $40 \mathrm{~mL}$ ratio of tissue to extractant solution that was scaled for capsule weight. The extractant solution contained $2 \%$ acetic acid and $10 \%$ ethanol in MilliQ ultra-pure water. A 90-minute extraction time was used with samples being shaken using a Ratek Orbital Mixer Incubator shaker (Ratek Instruments, Melbourne) (150 rpm, ambient temperature). After shaking, a $200 \mu \mathrm{L}$ aliquot of the extract solution was transferred to a Pall Acroprep Advance 96 filter plate $(0.45 \mu \mathrm{M})$ and filtered into a 96 well collection plate (Thermoline) under vacuum (Pall Vacuum Manifold).

Resulting samples were analysed using ultra-performance liquid chromatography (UPLC). A Walters Acquity UPLC BEH C18 column $(2.1 \mathrm{~mm} \times 100 \mathrm{~mm} \times 1.7 \mu \mathrm{m}$ particles $)$ was used. The Mobile phases were - Mobile Phase A: 2\% acetic acid in MilliQ ultra-pure water adjusted to $\mathrm{pH} 4.8 \pm 0.05$ with ammonia; Mobile Phase B: Acetonitrile - and the UPLC instrument settings and gradient were as described in Supplementary Table 1.

The program Empower2 was used for sample analysis with concentrations of individual morphinan alkaloids (morphine, oripavine, codeine and thebaine; MOCT) and total MOCT 
determined against standard concentrations and expressed on a percent weight for weight basis $(\% \mathrm{w} / \mathrm{w})$. Alkaloid \%w/w values were calculated as below:

$$
C_{\text {samp }}=\frac{A_{\text {samp }}}{A_{\text {std }}} \times C_{\text {std }}
$$

where:

$C_{\text {samp }}$ is alkaloid concentration in sample $(\% \mathrm{w} / \mathrm{w})$,

$C_{s t d}$ is alkaloid concentration in standard $\left(\mathrm{g} \mathrm{L}^{-1}\right)$,

$A_{\text {samp }}$ is peak area of alkaloid in sample $\left(\mu \mathrm{V} \mathrm{sec} \operatorname{sen}^{-1}\right)$ and

$A_{\text {std }}$ is peak area of alkaloid in standard $\left(\mu \mathrm{V} \sec ^{-1}\right)$.

\section{5 | Statistical analysis}

The effect of the timing of shading on final morphological capsule characteristics and alkaloid characteristics was assessed using the General Linear Model of the IBM SPSS Statistics software program. The timing of shading was included as a fixed factor and assessed against the residual. Where significant, Fishers Protected Least Significant Difference (LSD) post hoc test was used to compare means. Linear regressions and correlations were performed using $\mathrm{R}$ (R Core Team, 2017) to assess relationships among the parameters alkaloid yield per capsule, alkaloid concentration, capsule dry weight and capsule volume. Assumptions of homoscedasticity and normality were assessed and met.

\section{3 | Results}

\section{1 | Timing of floral initiation}

Floral initiation, defined as the emergence of floral meristem primordia from the inflorescence meristem (Smyth et al., 1990; Chandler, 2012), was first observed in this study (opium poppy genotype: Morphine PW11-3544) three weeks after sowing, in plants with 
seven fully expanded leaves and 10 nodes (Figure 1). Floral development as indicated by visible differentiation of floral structures such as stamen and gynoecium, had commenced by four weeks after sowing when plants had 10 leaves and 16 nodes.

\subsection{The effect of shade on final plant morphology}

The timing of shade during reproductive development had a significant effect on the height of the whole plant, vegetative stem and pedicel, the diameter of the vegetative stem and pedicel as well as the number of secondary capsules produced (Table 1). Pairwise comparisons revealed that plants shaded during floral initiation were $26 \%$ shorter overall compared to plants grown under full sun conditions, with significantly shorter and thinner vegetative stems and pedicels (Figure 2). The effect of shade at this time on pedicel height and vegetative stem diameter did not differ significantly from the effect of continuous shade, and the effect on pedicel diameter was very similar to the effect of continuous shade. Shade during floral growth also reduced overall plant height by $11 \%$ and pedicel height by $13 \%$ compared with non-shaded plants. Shade during floral development had no significant effect on vegetative stem height and diameter or pedicel diameter. Shade during capsule expansion had no significant effect on any of the aforementioned plant characteristics compared with non-shaded plants. Plants that were continuously shaded had significantly taller vegetative stems than all other plants, but reductions in pedicel height in these plants meant that overall plant height was not impacted.

\subsection{The effect of shade on capsule, seed and alkaloid characteristics}

Capsule morphology at harvest (capsule volume and dry weight), seed number and alkaloid characteristics (MOCT concentration and yield per capsule) were significantly affected by the timing of shade during reproductive development (Table 1). Plants shaded 
during floral initiation and floral growth produced smaller capsules, with lower dry weight, less alkaloid and fewer seeds than non-shaded plants. Capsule volume was $80 \%$ and $76 \%$ lower in plants shaded during floral initiation and floral growth, respectively, than plants that were never shaded, and alkaloid (MOCT) yield was 69\% and 54\% lower, respectively (Figure 3). Plants shaded during floral initiation and floral growth also produced $89 \%$ and $92 \%$ less seed, respectively, compared with non-shaded plants (Figure 4). Plants shaded continuously or during floral growth produced seeds that were $29 \%$ and $31 \%$ lighter, respectively than nonshaded plants. Shade during floral initiation, however, had no significant effect on individual seed weight (Figure 4). The effect of shade during floral initiation and floral growth on capsule dry weight, seed number and alkaloid yield was not significantly different from the effect of continuous shade. Shade during capsule growth resulted in significant increases in capsule dry weight by $31 \%$ and increases in alkaloid (MOCT) yield per capsule by $41 \%$ compared with non-shaded plants (although changes to capsule volume were non-significant). Capsules from plants that were shaded during floral initiation, floral development or shaded continuously had significantly higher concentrations of MOCT alkaloid than plants that were never shaded or shaded during capsule expansion. Increases in MOCT alkaloid concentration due to shading at these times, although significant, were of a much smaller magnitude than the observed decreases in MOCT alkaloid yield per capsule.

\section{4 | Relationships between final capsule morphology and alkaloid characteristics}

Final capsule morphology (dry weight and volume) was associated with alkaloid yield per capsule, as indicated by highly significant positive linear relationships between MOCT alkaloid yield per capsule and both capsule dry weight $\left(r^{2}=0.99, F_{1,7}=1053, P<0.001\right)$ and capsule volume $\left(r^{2}=0.97, F_{1,7}=210.4, P<0.001\right)$ among shaded, non-shaded and water deprived plants (Figure 5). This means that heavier, larger capsules yielded more MOCT 
alkaloid than lighter, smaller capsules. Conversely, the same capsule morphological parameters negatively impacted MOCT alkaloid concentration, with MOCT alkaloid present at lower concentrations in the tissue of heavier, larger capsules than in lighter, smaller capsules [alkaloid (MOCT) concentration and capsule dry weight $\left(r^{2}=0.81, F_{1,7}=29.14, P<\right.$ $0.01)$ and alkaloid (MOCT) concentration and capsule volume $\left(r^{2}=0.85, F_{1,7}=40.87, P<\right.$ $0.001)]$

\subsection{The effect of shade on MOCT alkaloid composition}

The timing of shade during reproductive development also had a significant impact on the relative concentration of predominant alkaloid compounds morphine, oripavine, codeine and thebaine within capsules (Table 1 and Figure 6). Relative morphine concentration (expressed as a proportion of the total amount of MOCT alkaloid extracted from each capsule) tended to be lower in capsules from plants shaded during floral initiation and floral development than those shaded during capsule expansion, continuously, or not at all (although the difference between plants shaded during floral initiation and during capsule expansion was not statistically significant). Consequently, the relative concentration of codeine and thebaine in capsules from these plants tended to increase. The relative concentration of thebaine was greatest in capsules from plants shaded during floral initiation and the relative concentration of codeine was greatest in capsules from plants shaded during floral development.

\section{4 | Discussion}

In this study we describe the timing of floral initiation and other key events during floral development in relation to weeks after sowing and macroscopic plant changes for the first time in opium poppy (genotype: Morphine PW11-3544). Floral initiation, defined as the 
appearance of floral meristem primordia developing from the inflorescence meristem (Smyth et al., 1990; Chandler, 2012), was first observed 3 weeks after seeds were sown in one individual when seven leaves had fully expanded. Floral development, as indicated by visible differentiation of floral structures such as stamen and gynoecium, commenced four weeks after sowing. This enabled us to test and confirm, in part, our first hypothesis that reducing carbohydrate supply to plants by shading them during floral initiation and early floral development results in lighter, smaller capsules with fewer seeds and lower alkaloid yield than shading during later capsule expansion. Although the effects of shading during floral initiation and floral development on capsule characteristics were not significantly different, plants that were shaded during floral initiation tended to have smaller, lighter capsules with fewer seeds and less total alkaloid. This suggests that growth during floral initiation, and to a lesser extent floral development, has a higher carbohydrate requirement and/or a lower sink strength than later expansive capsule growth. Conversely, shading during capsule growth enhanced capsule dry weight, capsule volume and alkaloid yield per capsule. This may be due to the increased relative sink strength of the capsule during this time at the expense of reduced vegetative growth, or possibly an increase in the water available for cell expansion because of reduced transpiration. Resolving the timing of the transition from vegetative to reproductive development in opium poppy and the sensitivity of development at this time to low irradiance indicates that growers need to avoid management practices that impinge significantly on photosynthesis during early reproductive development and highlights the vulnerability of seed production, and thus, plant fitness, to stress at this stage. The positive linear relationship between capsule size, seed number, and alkaloid yield also raises the possibility that any factor that alters capsule growth may affect alkaloid yield and reproductive success.

We also demonstrated that shade during floral initiation and floral development lowered the relative concentration of morphine and hence increased the relative concentration of thebaine, 
oripavine, and codeine. This is contrary to our hypothesis that the relative concentrations of precursors to morphine (thebaine, oripavine, and codeine) would be lowered by an extended period of growth in plants shaded during early reproductive development. Shade during later capsule expansion had little effect on alkaloid composition. Thus, shade during early floral development not only reduces opium poppy capsule size, seed number and total alkaloid yield, it also alters alkaloid composition at capsule maturity. Conversely, shade during later expansive capsule growth led to larger capsules and higher alkaloid yield with no impact on alkaloid composition.

\section{1 | Timing of floral initiation}

Floral initiation occurred 3 weeks after sowing in plants that received abundant light, nutrients and water. However, reproductive development in opium poppy is understood to be highly dependent on environmental conditions (Wang et al., 1997) and agronomic practices (Bernáth, 1998). For example, the time between cotyledon appearance and primary bud emergence is negatively correlated with light intensity and temperature (Bernáth, 1998).

4.2 Shading during early reproductive development irreversibly restricts growth

Low light intensity during plant development reduces photosynthetic gains (Boardman, 1977) and negatively affects whole plant growth in opium poppy, including the rate of development, final capsule dimensions and alkaloid content (Bernáth \& Tétényi, 1979). In agreement with this earlier work, we found that shading plants during floral initiation impedes plant and capsule growth compared with unshaded plants. Plants shaded at this time were significantly shorter overall, with shorter and thinner vegetative stems and pedicels. Most capsule and alkaloid characteristics recorded were constrained by shading during floral initiation and to a lesser extent during floral development. This effect was 
similar to that of continuous shade meaning that plants could not later compensate for restricted early growth. Plants grown under continuous shade conditions, however, produced significantly taller vegetative stems than unshaded plants, an characteristic indicative of the well-researched shade avoidance syndrome (Franklin \& Whitelam, 2005). The taller vegetative stems thus demonstrate that resource partitioning within the plant to support growth has changed in response to environmental stimuli. In this case, continued stem growth and internode elongation in plants grown under continuous shade may have reduced the resources available for leaf growth, developing floral tissue and, later, development of the capsule and seed. Seed number per capsule and individual seed weight were both negatively affected by shade during floral growth and continuous shade, indicating a deficit of carbohydrate resources to support development during this period. While the number of seeds produced per capsule was reduced by shading plants during floral initiation, individual seed weight in these plants was not significantly different from plants grown under full sun. Furthermore, shade during floral initiation and continuous shade decreased the number of secondary capsules produced. This observation is consistent with observations from other species, where shade applied prior to flowering reduces the number of buds produced (Kohri et al., 1998). This response is likely due to lower availability of carbohydrate resources to support reproductive development as has been observed in other crops including soybeans (Kohri et al., 1998).

\subsection{Are smaller capsules a consequence of reduced cell division?}

Shading plants for three weeks during floral initiation and early floral development resulted in unrecoverable restriction of capsule development with a substantially lower final capsule volume, dry weight, and alkaloid yield. The slightly higher total alkaloid concentration of the smaller capsules produced by plants shaded at this time did not 
compensate for the effect of reduced capsule size on alkaloid yield per capsule. The negative impact of shade during early reproductive development on final capsule size in opium poppy is in agreement with the results of earlier studies on other species (Baldet et al., 2002). As was observed from photomicrographs of the developing floral meristem, this period of growth is characterized by a primary phase of cell division and differentiation as floral organs develop, particularly the gynoecium, to later become the capsule. In many species, early floral development has a high demand for carbohydrates to support shoot growth, increasing cell differentiation and floral organogenesis (Lovett-Doust \& Lovett-Doust, 1988). Thus, reducing carbohydrate supply to the developing opium poppy flower during early floral development may reduce the final number of cells produced, which would likely have irreversible impacts on final capsule size. For example, in apricot, cell number is a more important determinant of final fruit size than cell volume (Coombe, 1976). We propose a similar response in opium poppy in which final capsule morphology can be at least partially determined by six weeks after sowing. The fact that vegetative growth was also negatively impacted by shade suggests that carbohydrates were not necessarily diverted from developing flowers to vegetative organs. Instead, it seems that plant growth was generally inhibited by shading during early floral growth, although neither root nor leaf growth were quantified in this study.

Shade applied immediately following floral initiation also led to smaller capsules and lower total alkaloid yield per capsule. This period of plant growth encompassed vegetative growth, internode and pedicel elongation, and floral organ development (including development of the gynoecium, later capsule). Previous work on this species identified the phase immediately after floral initiation as having the greatest requirement for the uptake of water and nutrients compared with development at anthesis or later (Bernáth, 1998). Because shading immediately following floral initiation was found in this study to have a similarly negative 
effect on final capsule characteristics as shading prior to and during floral initiation, these periods of growth likely share a high carbohydrate requirement.

4.4 | Final capsule size and alkaloid yield is enhanced by shading during capsule expansion Plants that were shaded during last phase of capsule expansion had a $41 \%$ greater alkaloid yield per capsule than the non-shaded control plants because capsules were larger and alkaloid concentration was only slightly lower. The enhancement of capsule growth in opium poppy by shading during later capsule expansion shown in this study is consistent with the previously observed effect of defoliation following veraison on fruit size in grape vine (Hunter \& Visser, 1990). This final phase encompassed poppy capsule development from bud emergence prior to the hook stage through to approximately five days following anthesis. During this period of growth the stem continues to elongate, anthesis occurs, the capsule at the "green" stage expands, leaf expansion ceases, petals fall and further capsule expansion occurs (Bernáth, 1998). Capsule growth at this stage is likely dominated by cell expansion (Gillaspy et al., 1993; Renaudin et al., 2017), which is constrained more by the availability of water than carbohydrates (Coombe, 1976) and vegetative sink demands are decreasing. Thus, the lower demand for carbohydrates at this time in opium poppy capsule development may be more easily met with less competition from vegetative sinks than during earlier development. Alternatively, the growing capsule may simply be a stronger sink for carbohydrates than other plant organs (Ho, 1988), however vegetative growth did not appear to be disadvantaged in favour of capsule growth in these plants (although as mentioned above root and leaf growth was not measured in this study).

Another possible explanation for larger capsules associated with shading at this time is that apoplast water potential may be higher when plants are shaded. This is because shade conditions tend to lower transpirational water loss from plants due to stomatal closure and 
reduced evaporative demand, resulting in a steeper water potential gradient towards growing cells (Kozlowski, 1972). For example, increased fruit volume has been observed following the application of antitranspirants (a wax emulsion film) to the leaves of peach (Prunus persica) trees which block stomata and reduce water loss (Davenport et al., 1972). However, endoreduplication, the amplification of the genome in the absence of mitosis, also contributes to rapid cell expansion in tomato (Bergervoet et al., 1996), and it is not known what proportion of cell expansion is driven by which process. On the other hand, cell expansion in shaded leaves of Arabidopsis thaliana occurs independently of endoreduplication, in that endoreplication was reduced by decreasing light intensity (Cookson et al., 2006).

\section{5 | Larger capsules have more alkaloid}

In this study, across all treatments, a strong positive association was observed between total alkaloid yield and capsule volume and a weak negative relationship between alkaloid concentration and capsule volume. This demonstrates that larger capsules contain more alkaloid despite having slightly lower concentrations of MOCT alkaloid compounds than smaller capsules. These results suggest that the final volume of the capsule is a critical indicator and contributor to the total MOCT alkaloid yield from each plant. Thus, achieving maximum capsule size is key to maximising potential crop yield. This conclusion is consistent with findings of previous studies (Mika, 1955; Yadav et al., 2006) and principles of traditional breeding methods in which the highest opium yield is achieved through maximising capsule size and number of capsules produced per plant (Bernáth, 1998). Our data also suggests that larger capsules produce more seed, so a proportional increase in alkaloid production would be advantageous if these secondary metabolites protect seeds against herbivory. 


\section{6 | Shade during early reproductive development alters alkaloid composition}

The relative concentration of predominant alkaloid compounds morphine, oripavine, codeine and thebaine (MOCT) within capsules varied among plants that were shaded at different times during reproductive development. Most notably, relative morphine concentration decreased while the relative concentrations of codeine, oripavine, and thebaine increased in plants shaded during floral initiation and early floral growth. These results differ from the trend outlined by Bernáth \& Tétényi (1979) of decreasing codeine and thebaine concentration in the capsules of plants shaded before the transition to reproductive growth. These differences may be due to variation in the timing of events in alkaloid biosynthesis or a result of cultivar differences (Bernáth \& Tétényi, 1979). Nevertheless, significant variation in the relative concentration of MOCT alkaloids in this study does illustrate more disruption to the biosynthesis pathway by shade during early reproductive development compared with shade at later stages. That other indices of whole plant development were also detrimentally impacted by shade at this time suggests that multiple processes were constrained. Further study is needed to understand the mechanism of this disruption. Differences in relative concentration may be due to a similar reduction in the rate of morphine synthesis from precursor compounds as seen in overall plant growth. In this theory, shade conditions experienced during floral initiation and early floral growth may have created an accumulation of precursor compounds with less time after return to full light conditions and before the onset of capsule desiccation for further synthesis to morphine. Additionally, the relative concentration of alkaloids produced by continuously shaded plants did not differ from nonshaded plants indicating a standard conversion rate from precursor compounds to morphine under consistent growing conditions.

\section{6 | Conclusion}


Floral initiation in opium poppies grown under controlled conditions occurs 3 weeks after sowing when 10 leaf nodes have developed. Shade at this time (i.e. during the transition from vegetative to reproductive growth) and during subsequent early reproductive development dramatically reduced final capsule size, total alkaloid yield per capsule and seed number per capsule compared with plants grown under continuous full sun conditions. Conversely, shade during later capsule expansion enhanced capsule size and total alkaloid yield. Shade during early reproductive development also had a greater effect on the relative concentration of predominant morphinan alkaloids at harvest than shade during later developmental stages. Under these conditions the relative concentration of morphine in capsule tissue was lower and the relative concentration of precursors, thebaine, oripavine, and codeine was higher than in non-shaded plants. These findings highlight the sensitivity of these early stages of capsule development to short-term shading. We suggest that shade during early floral development inhibits the normally rapid cell division that occurs at this time resulting in smaller capsules because demand for carbohydrates is not met. Conversely, shade during late capsule expansion enhances capsule size because capsule development at this time is likely dominated by cell expansion that is largely limited by the availability of water not carbohydrates. A close association between capsule size and alkaloid yield per capsule means that total alkaloid produced is affected by shade at these developmental stages in a similar way to capsule size. The higher relative concentration of precursor alkaloids in plants shaded during early floral development suggests that key steps in the morphinan biosynthetic pathway are disrupted by shade at this time. Further research is required to test these hypotheses. Nonetheless, this study demonstrates that capsule and seed development, and alkaloid production requires a substantial carbon investment very early during reproductive development that cannot be compensated for during later growth. 


\section{Funding}

This work was supported by a Tasmanian Alkaloids Pty Ltd study scholarship.

\section{Acknowledgements}

We thank Tasmanian Alkaloids Pty Ltd for providing us with seed. We also thank Ella Matusiak from Tasmanian Alkaloids Pty Ltd for assistance with alkaloid extraction and analysis, and Phil Andrews and Caroline Claye from the University of Tasmania for glasshouse and laboratory support.

\section{References}

Baldet, P., Devaux, C., Chevalier, C., Brouquisse, R., Just, D., \& Raymond, P. (2002). Contrasted responses to carbohydrate limitation in tomato fruit at two stages of development. Plant, Cell and Environment, 25, 1639-1649.

Beaudoin, G., \& Facchini, P. (2014). Benzylisoquinoline alkaloid biosynthesis in opium poppy. Planta, 240, 19-32.

Becker, A., Gleissberg, S., \& Smyth, D. (2005). Floral and vegetative morphogenesis in California Poppy (Eschscholzia californica Cham.) International Journal of Plant Science, 166, 537-555.

Bergervoet, J., Berhoeven, H., Gilissen, L., \& Bino, R. (1996). High amounts of nuclear DNA in tomato (Lycopersicon esculentum Mill.) pericarp. Plant Science, 116, 141-145. 
Bernáth, J. (1998). Poppy the genus Papaver, Amsterdam, The Netherlands: Harwood Academic Publishers.

Bernáth, J., \& Tétényi, P. (1979). The effect of environmental factors on growth. Development and alkaloid production of poppy (Papaver somniferum L.) I. Responses to day length and light intensity. Biochemie und Physiologie der Pflanzen, 174, 468-478.

Bird, D.A., Franceschi, V.R., \& Facchini, P.J. (2003). A tale of three cell types: alkaloid biosynthesis is localized to sieve elements in opium poppy. The Plant Cell, 15, 2626-2635.

Boardman, N.K. (1977). Comparative photosynthesis of sun and shade plants. Annual review of Plant Physiology, 28, 355-377.

Chandler, J. (2012). Floral meristem initiation and emergence in plants. Cellular and Molecular Life Sciences, 69, 3807-3818.

Cookson, S.J., Radziejwoski, A., \& Granier, C. (2006). Cell and leaf size plasticity in Arabidopsis: what is the role of endoreduplication? Plant, Cell \& Environment, 29, 12731283.

Coombe, B.G. (1976). The development of fleshy fruits. Annual Review of Plant Physiology, 27, 507-528.

Davenport, D., Fisher, M., \& Hagan, R. (1972). Some counteractive effects of antitranspirants. Plant Physiology, 49, 722-724.

Evert, R. (2006). Internal secretory structures. In Esau's plant anatomy, pp. 473-501. Eds R. Evert \& S. Eichhorn. Hoboken, New Jersey: John Wiley \& Sons, Inc.

Facchini, P.J., \& De Luca, V. (1995). Phloem-specific expression of tyrosine/dopa decarboxylase genes and the biosynthesis of isoquinoline alkaloids in opium poppy. The Plant Cell, 7, 1811-1821.

Franklin, K., \& Whitelam, G. (2005). Phytochromes and Shade-avoidance Responses in Plants. Annals of Botany, 96, 169-175. 
Gillaspy, G., Ben-David, H., \& Gruissem, W. (1993). Fruits: A Developmental Perspective. The Plant Cell, 5, 1439-1451.

Hagel, J., Yeung, E., \& Facchini, P. (2008). Got milk? The secret life of laticifers. . Trends in Plant Science, 13, 631-639.

Harvest, T., Brown, P., Fist, A., Gracie, A., Gregory, D., \& Koutoulis, A. (2009). The latex capacity of opium poppy capsules is fixed early in capsule development and is not a major determinant in morphine yield. Annals of Applied Biology, 154, 251-258.

Ho, L. (1988). Metabolism and compartmentation of imported sugars in sink organs in relation to sink strength. Annual Review of Plant Physiology and Plant Molecular Biology, 39, 355-378.

Hunter, J., \& Visser, J. (1990). The Effect of Partial Defoliation on Growth Characteristics of Vitis vinifera L. cv Cabernet Sauvignon II. Reproductive Growth. South African Journal of Enology + Viticulture, 11, 26-32.

Kohri, K., Saitoh, K., Kuroda, T., \& Kumano, S. (1998). Significance of flower differentiation and development in the process of determining soybean yield - Effects of shading treatment on the number of floral buds and pod sets. Japanese Journal of Crop Science, 67.

Kozlowski, T. (1972). Plant Responses and Control of Water Balance, Cambridge, USA: Academic Press.

Kriedemann P. (1986) Stomatal and photosynthetic limitations to leaf growth. Functional Plant Biology, 13, 15-31.

Lee, E., Hagel, J., \& Facchini, P. (2013). Role of the phloem in the biochemistry and ecophysiology of benzylisoquinoline alkaloid metabolism. Frontiers in Plant Science, 4, 1-7. Lee, E.-J., \& Facchini, P. (2010). Norcoclaurine synthase is a member of the pathogenesisrelated 10/Bet v1 protein family. The Plant Cell, 22, 3489-3503. 
Leonard, E.R. (1962). Inter-relations of vegetative and reproductive growth, with special reference to indeterminate plants. Botanical Review, 28, 353-410.

Link, H. (2000). Significance of flower and fruit thinning on fruit quality. Journal of Plant Growth Regulation, 31, 17-26.

Lovett-Doust, J., \& Lovett-Doust, L. (1988). Plant Reproductive Ecology: Patterns and Strategies, New York: Oxford University Press.

Mahdavi-Damghani, A., Kamkar, B., Al-Ahmadi, M., Testi, L., Muñoz-Ledesma, F., \& Villalobos, F. (2010). Water stress effects on growth, development and yield of opium poppy (Papaver somniferum L.). Agricultural Water Management, 97, 1582-1590.

Matthews, M., \& Anderson, M. (1988). Fruit ripening in grapes (Vitis vinifera L.): responses to seasonal water deficits. American Journal of Enology and Viticulture, 39, 313-320.

Mika, E. (1955). Studies on the growth and development and morphine content of opium poppy. Botanical Gazette, 116, 323-339.

Morandi, B., Grappadelli, L., Rieger, M., \& LoBianco, R. (2008). Carbohydrate availability affects growth and metabolism in peach fruit. Physiologia Plantarum, 133, 229241.

R Core Team. (2017). R: a language and environment for statistical computing. Vienna, Austria: R Foundation for Statistical Computing.

Renaudin, J., Deluche, C., Cheniclet, C., Chevalier, C., \& Frangne, N. (2017). Cell layerspecific patterns of cell division and cell expansion during fruit set and fruit growth in tomato pericarp. Journal of Experimental Botany, 68, 1613-1623.

Samanani, N., Alcantara, J., Bourgault, R., Zulak, K. G., \& Facchini, P. J. (2006). The role of phloem sieve elements and laticifers in the biosynthesis and accumulation of alkaloids in opium poppy. The Plant Journal, 47, 547-563. 
Singh, S., Yadav, H., Shukla, S., \& Chatterjee, A. (2003). Studies on different selection parameters in opium poppy (Papaver somniferum). Journal of Medicinal and Aromatic Plant Sciences, 25, 8-12.

Smyth, D., Bowman, J., \& Meyerowitz, E. (1990). Early flower development in Arabidopsis. The Plant Cell, 2, 755-767.

Strenlin, M., \& Aizen, M. (2018). The interplay between ovule number, pollination and resources as determinants of seed set in a modular plant. Peer Journal, 6, 1-19.

Turner, N. (1990). Plant Water Relations and Irrigation Management. Agricultural Water Management, 17, 59-73.

Wang, Z., Acock, M., \& Acock, B. (1997). Phases of Development to Flowering in Opium Poppy (Papaver somniferum L.) under Various Temperatures. Annals of Botany, 80, 547552.

Wardlaw, I. (1990). Tansley Review No. 27: The control of carbon partitioning in plants. New Phytologist, 116, 341-381.

Wardlaw, I.F. (1968). The control and pattern of movement of carbohydrates in plants. Botanical Review, 34, 79-105.

Yadav, H., Shukla, S., \& Singh, S. (2006). Genetic variability and interrelationship among opium and its alkaloids in opium poppy (Papaver somniferum L.). Euphytica, 150, 207-214.

Zhou, L., Christopher, D., \& Paull, R. (2000). Defoliation and fruit removal effects on papaya fruit production, sugar accumulation, and sucrose metabolism. Journal of the American Society for Horticultural Science, 125, 644-652.

Table 1. Results of analysis of variance (ANOVA) tests for the effect of the timing of shade during reproductive development on opium poppy morphological traits (degrees of freedom $=$ 4/53). Significant effects are shown in bold. 


\begin{tabular}{|c|c|c|}
\hline Trait & $F$ & $P$ \\
\hline Vegetative Characteristics & & \\
\hline Plant Height $(\mathrm{cm})$ & 9.358 & $<0.001$ \\
\hline Vegetative Stem Height $(\mathrm{cm})$ & 16.149 & $<0.001$ \\
\hline Pedicel Height $(\mathrm{cm})$ & 15.366 & $<0.001$ \\
\hline Vegetative Stem Diameter $(\mathrm{mm})$ & 7.065 & $<0.001$ \\
\hline Pedicel Diameter $(\mathrm{mm})$ & 21.337 & $<0.001$ \\
\hline Secondary Capsules & 2.583 & 0.048 \\
\hline Capsule Characteristics & & \\
\hline Capsule Volume $\left(\mathrm{cm}^{3}\right)$ & 42.882 & $<0.001$ \\
\hline Capsule Dry Weight (g) & 48.092 & $<0.001$ \\
\hline MOCT Concentration $(\% \mathrm{w} / \mathrm{w})$ & 4.644 & $\mathbf{0 . 0 0 3}$ \\
\hline MOCT Yield Capsule $^{-1}(\mathrm{mg})$ & 27.967 & $<0.001$ \\
\hline Seed Number per Capsule & 10.986 & $<0.001$ \\
\hline Individual Seed Weight (mg) & 10.714 & $<0.001$ \\
\hline MOCT Alkaloid Relative Concen & & \\
\hline Morphine (\% of combined total) & 5.007 & 0.002 \\
\hline Oripavine (\% of combined total) & 4.182 & 0.005 \\
\hline Codeine (\% of combined total) & 9.890 & $<0.001$ \\
\hline Thebaine (\% of combined total) & 3.502 & 0.013 \\
\hline
\end{tabular}

\section{Figure legends}


Figure 1. Profile of key events during reproductive development in opium poppy, showing the transition from vegetative to reproductive growth by 4 weeks after sowing. Grey bars on the left show the number of expanded leaves and leaf nodes accumulated by the same plant from which each corresponding photomicrograph on the right was taken to illustrate the developmental landmarks taking place in the apical meristem. Scale bars represent $100 \mu \mathrm{m}$ in images $\mathrm{A}, \mathrm{B}, \mathrm{C}, \mathrm{E}, \mathrm{F}$, and $500 \mu \mathrm{m}$ in image D.

Figure 2. The effect of shading during key opium poppy reproductive developmental stages on final plant morphology in terms of (A) vegetative stem height, (B) flower pedicel height, (C) vegetative stem diameter and (D) secondary capsules produced per plant. Columns are mean values \pm standard error. Significant differences among treatments are indicated by lower case letters above columns $(P<0.05)$.

Figure 3. The effect of shading during key opium poppy reproductive developmental stages on final capsule characteristics ((A) capsule volume and (B) capsule dry weight) and alkaloid characteristics ((C) MOCT alkaloid concentration and (D) MOCT alkaloid yield per capsule). Columns are mean values \pm standard error. Significant differences among treatments are indicated by lower case letters above columns $(P<0.05)$.

Figure 4. The effect of shading during key opium poppy reproductive developmental stages on (A) individual seed dry weight ( $\mathrm{mg}$ ) and (B) number of seeds per capsule. Columns are mean values \pm standard error. Significant differences among treatments are indicated by lower case letters above columns $(P<0.05)$.

Figure 5. Relationships between final capsule morphology (dry weight and volume) and MOCT alkaloid characteristics (yield per capsule and concentration) among opium poppy plants that were droughted or shaded at different stages of reproductive development. Symbols are mean values \pm standard error. Significant linear regressions describe the relationships between (A) alkaloid (MOCT) yield per capsule and capsule dry weight; alkaloid $($ MOCT $)$ yield per capsule $=16.762 \times$ capsule dry weight $+0.729\left(r^{2}=0.99, F_{1,7}=\right.$ 1053, $P<0.001$ ), (B) alkaloid (MOCT) yield per capsule and capsule volume; alkaloid $($ MOCT $)$ yield per capsule $=2.428 \times$ capsule volume $+1.557\left(r^{2}=0.97, F_{1,7}=210.4, P<\right.$ $0.001),(\mathrm{C})$ alkaloid (MOCT) concentration and capsule dry weight $(1 / \sqrt{ }(\mathrm{y})$ transformed data); alkaloid $(\mathrm{MOCT})$ concentration $=0.122 \times$ capsule dry weight $+0.638\left(r^{2}=0.81, F_{1,7}=29.14\right.$, $P<0.01)$ and (D) alkaloid (MOCT) concentration and capsule volume $(1 / \sqrt{ }(\mathrm{y})$ transformed data); alkaloid $(\mathrm{MOCT})$ concentration $=0.018 \times$ capsule volume $+0.641\left(r^{2}=0.85, F_{1,7}=\right.$ 40.87, $P<0.001)$.

Figure 6. The effect of shading during key opium poppy reproductive developmental stages on the relative concentration of MOCT alkaloids. Columns are mean relative concentrations of morphine, oripavine, codeine and thebaine alkaloids expressed as a percentage of total MOCT alkaloid \pm standard error. Significant differences among treatments are indicated by lower case letters beside discrete column sections $(P<0.05)$. 


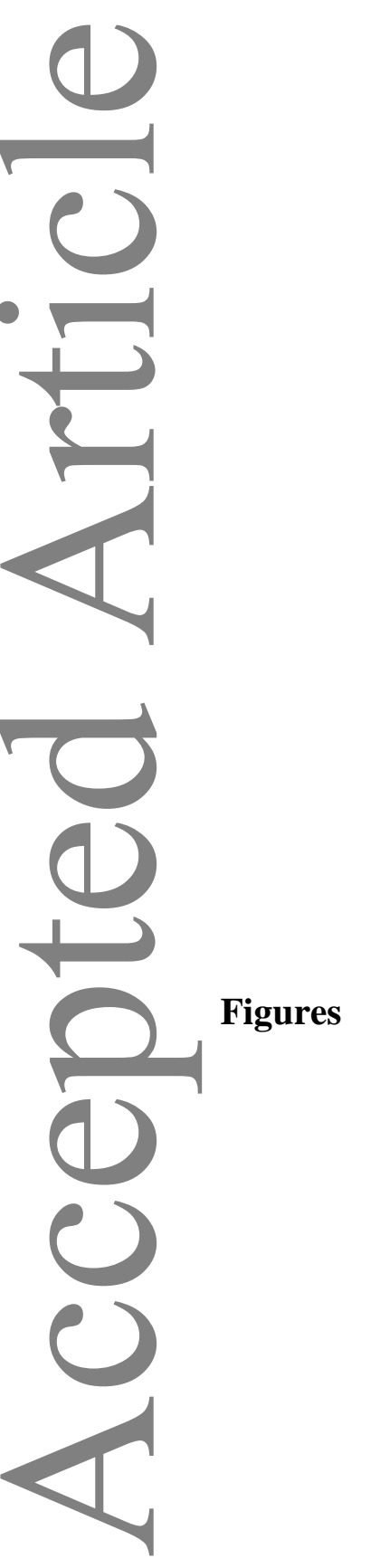




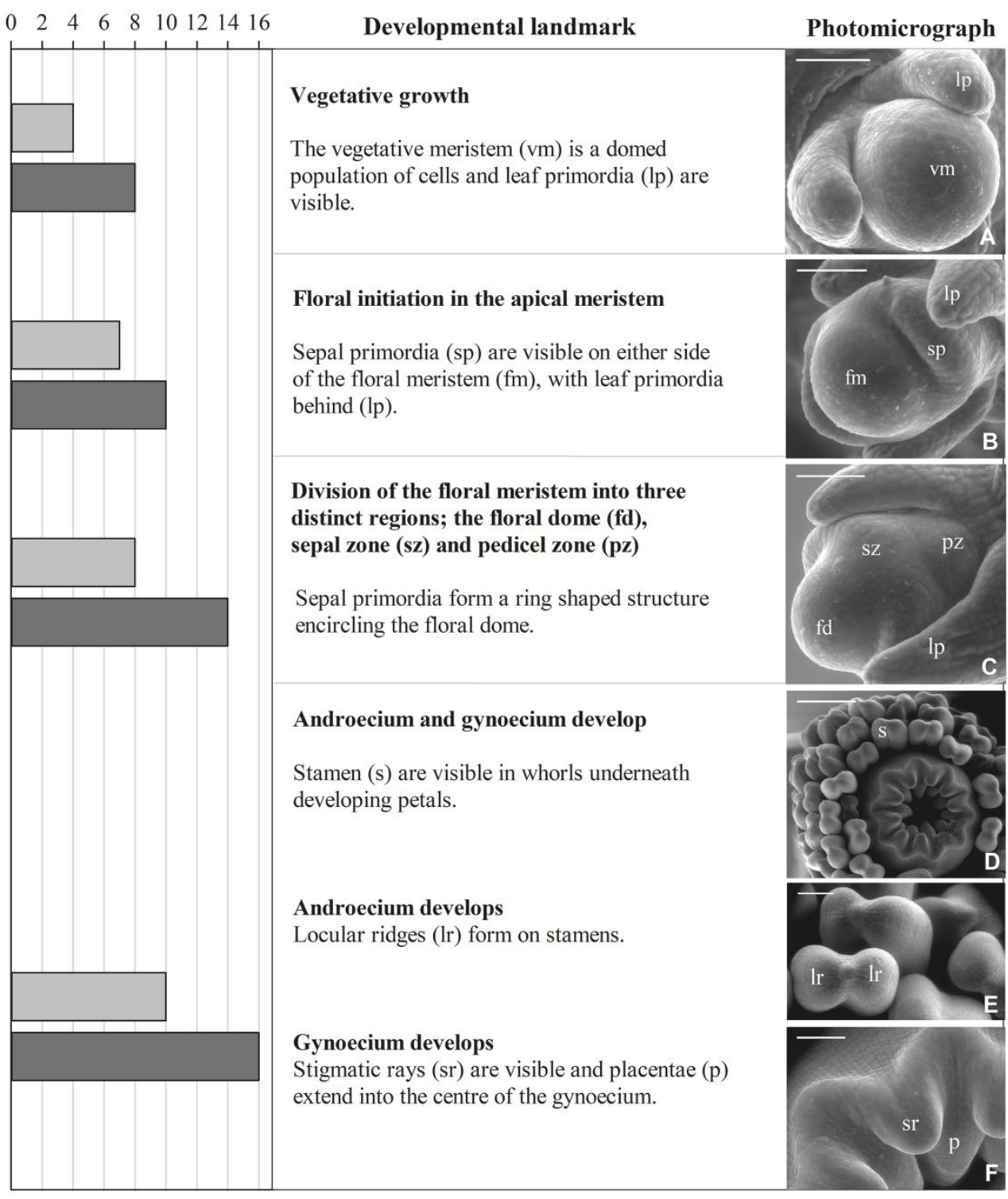

Number of nodes

Number of leaves $>1 \mathrm{~cm}$ 


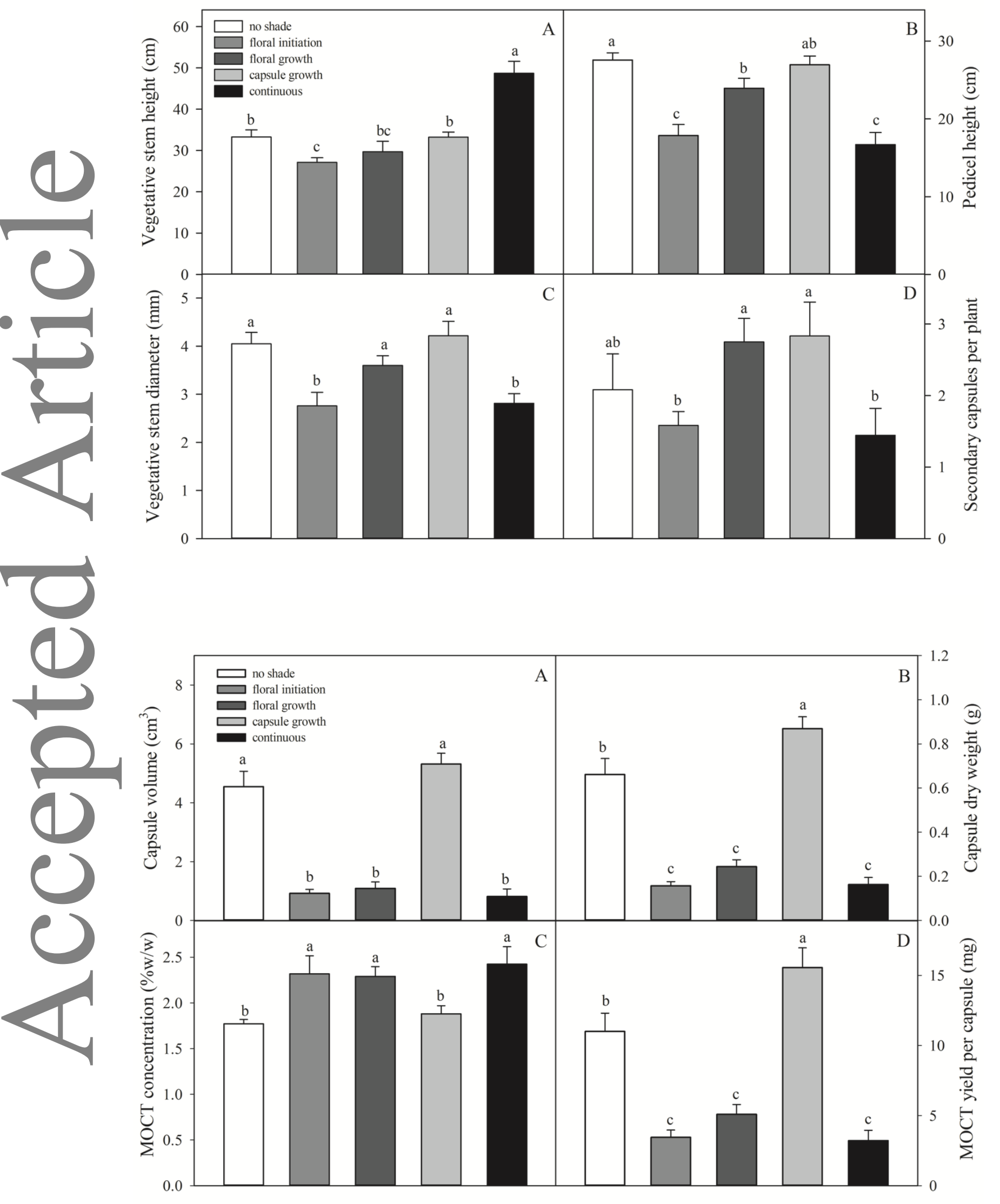



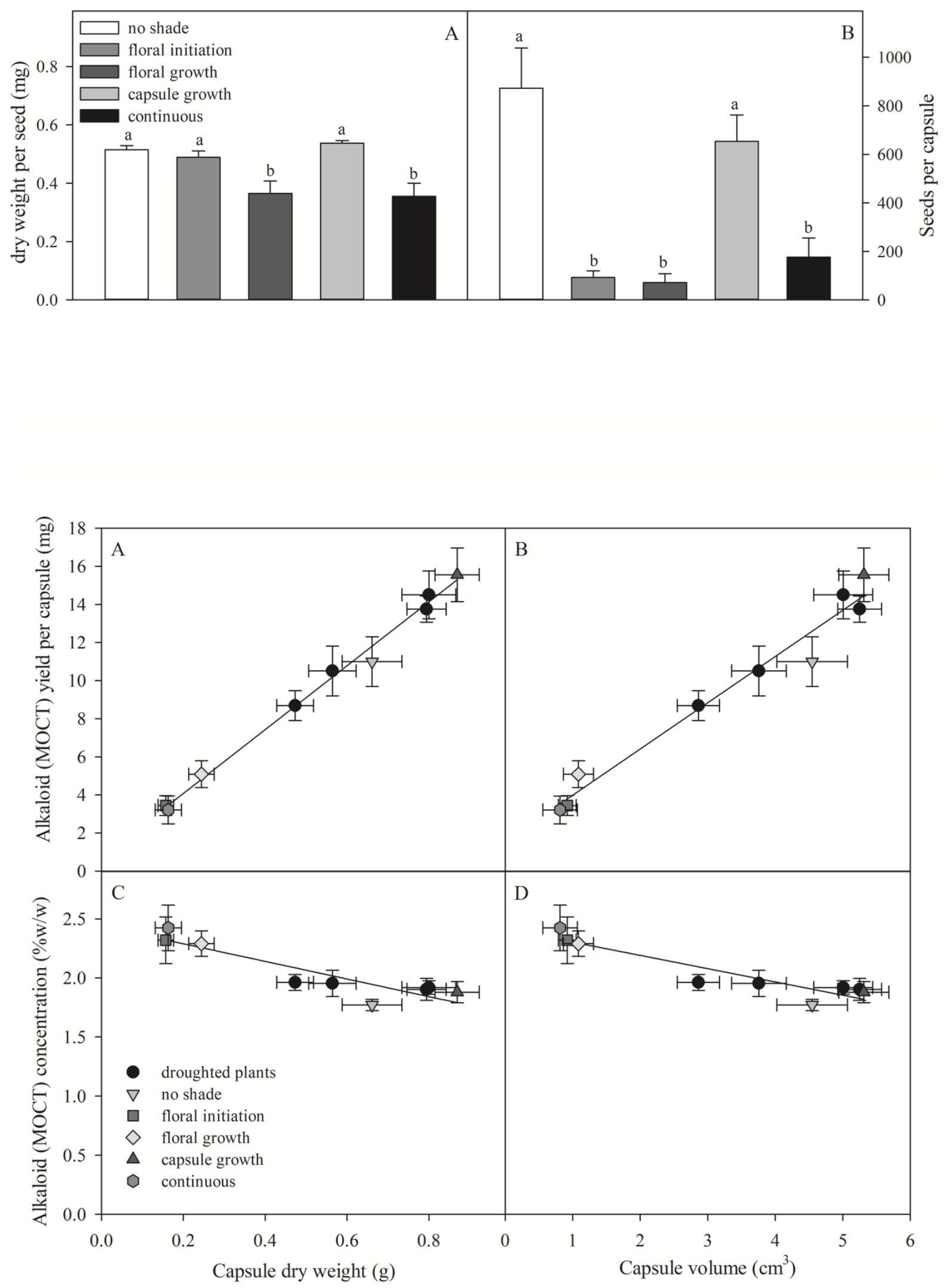
